\title{
DEMOCRACIA E TECNOLOGIA: NOS CAMINHOS DO “ATOR NÃO SOCIAL”
}

\author{
DEMOCRACY AND TECHNOLOGY: ON THE WAYS OF THE "NON SOCIAL ACTOR"
}

Itamar Soares Veiga*

\begin{abstract}
RESUMO
Alain Touraine defende uma concepção de sujeito que está na contracorrente dos críticos do século XX. O sujeito constitui a base para o ator que se desenvolve no espaço aberto das democracias. Este artigo acompanha a mudança na sua concepção de ator: o ator social se torna ator não social. A mudança é apresentada por meio do posicionamento crítico de Touraine diante da obra de Foucault. O objetivo é mostrar quais são as ameaças ao sujeito no espaço disponível da democracia. Essas ameaças constituirão um fator não desprezível na explicação da crise da democracia. A resposta alcançada afirma que não apenas o discurso interpretativo dominante se constitui uma ameaça, mas alguns desenvolvimentos tecnológicos como coleta de dados e manipulação podem também ser uma ameaça.

PALAVRAS-CHAVE: Touraine. Sujeito. Ator não social. Democracia. Tecnologia.
\end{abstract}

\begin{abstract}
Alain Touraine defends a conception of subject that is in the countercurrent of the critics of the twentieth century. The subject forms the basis for the actor that develops in the open space of democracies. This article accompanies the change in his conception of actor: the social actor becomes non-social actor. The change is presented through the critical positioning of Touraine in the face of Foucault's work. The objective is to show what the threats are to the subject in the available space of democracy. These threats will be a not inconsiderable factor in explaining the crisis of democracy. The answer is that not only dominant interpretive discourse is a threat, but some technological developments such as data collection and manipulation can also be a threat.
\end{abstract}

KEY-WORDS: Touraine. Subjects. Non-social actor. Democracy. Technology.

Um dos temas da filosofia política é a democracia, e no centro da democracia se encontra a pessoa individual com seus direitos e seus deveres. A pessoa individual pode ser denominada de sujeito. Entretanto, a palavra "sujeito" possui conotações diferentes que anunciam percursos distintos ao longo da história da filosofia até os dias de hoje. Na época atual há um redirecionamento inverso a respeito do conceito de sujeito: ele é objeto de uma crítica desde meados do século XIX. No âmbito bem mais recente, encontramos outros trabalhos desenvolvidos por filósofos e sociólogos, dentre os quais destacamos Alain Touraine.

\footnotetext{
* Doutor em Filosofia, professor de filosofia do PPG de Filosofia da Universidade de Caxias do Sul - UCS. Email: inpesquisa@yahoo.com.br.
} 
O tema do sujeito pode ser desenvolvido como uma forma de compreender o mundo tecnológico e a disseminação de dispositivos por meio do consumo. É relativo a essa disseminação que se começa a questionar a influência da tecnologia nas decisões pessoais e coletivas, o que influi na democracia. O mundo tecnológico está em franco desenvolvimento, e a análise de suas influências específicas sobre a constituição ou sobre a sobrevivência do sujeito ainda está para ser mais aprofundada. Não sabemos ainda qual será o papel do sujeito futuro dentro do mundo tecnológico, inclusive temos pouca clareza da permanência do sujeito livre e autônomo neste mundo tecnológico. Esses aspectos serão mostrados ao longo deste artigo.

No que diz respeito à filosofia e à discussão em geral nas ciências humanas, há uma tarefa a ser desenvolvida: a abertura do espaço para uma investigação sobre as relações entre a tecnologia e a nossa sociedade, com uma ênfase na política e nas lutas dos mais variados tipos. Uma pesquisa que pode contribuir para a abertura de um espaço é o acompanhamento da evolução do pensamento de Alain Touraine. Touraine é um reconhecido sociólogo que se destacou não somente numa defesa do sujeito, mas também como um pensador preocupado com a democracia.

Os questionamentos em torno do tema do sujeito influem na compreensão de base da construção democrática. Sujeito, nesse caso, significa autonomia e liberdade na tomada de decisões e, como enfatiza Touraine, um "combate": "O sujeito é, mais do que uma palavra libertadora, uma ação e uma consciência que, no mais das vezes, não se afirmam senão pelo combate contra as forças organizadas que, dando embora uma existência concreta ao sujeito, ameaçam destruí-lo.” (TOURAINE, 2006, p. 26). Este artigo procura mostrar quais são as ameaças ao sujeito no espaço disponível da democracia. A hipótese é a de que essas ameaças não somente provêm do âmbito do discurso que domina e prevalece, mas também, dos dispositivos tecnológicos, principalmente os mais atuais. Se a hipótese é verdadeira, a inserção da tecnologia dentro dessas ameaças ao sujeito significa uma ampliação da reflexão de Touraine.

O texto se divide em duas partes. Na primeira parte vamos nos deter no discurso que predomina e prevalece, este discurso é denominado de discurso interpretativo dominante. Para mostrar as suas peculiaridades, vamos acompanhar a observação crítica que Touraine faz a respeito de Foucault. $\mathrm{Na}$ segunda parte, o discurso interpretativo dominante deve gradativamente ceder espaço aos desenvolvimentos tecnológicos. Isso vai mostrar outra face da invisibilidade do poder e constituir uma espécie de novo enfretamento ao sujeito defendido 
por Touraine. Por fim, a conclusão mostrará quais os resultados possíveis dessas ameaças à concepção de sujeito e de ator (seja este um ator não social ou ainda residualmente um ator "social") em nossas democracias imersas em tecnologia.

\section{O DISCURSO INTERPRETATIVO DOMINANTE}

No seu livro Crítica da modernidade (Crítique de La modernité - 1992), Touraine escreve seção a Foucault intitulada "Michel Foucault, o poder e os sujeitos". Ele faz uma crítica, e essa crítica não é negativa e nem possui caráter refutador. Touraine se preocupa com o tema do sujeito e considera que esse tema está deslocado no conjunto dos escritos de Foucault publicado até então. Segundo Touraine, Foucault trataria o tema do sujeito de um modo mais abrangente do que deveria. Essa abrangência assumia a normalização e governabilidade como constituintes do sujeito. Touraine diz que Foucault enfatizou esses constituintes justamente para se opor a uma concepção idealista de sujeito:

Foucault poderia ter dado uma importância mais central à ideia de Sujeito, mas ele queria eliminar tão vigorosamente a visão idealista do Sujeito e da história que tinha dominado a primeira metade de sua obra, notadamente Le mots et les choses, que ele deu o lugar central ao tema do poder, único capaz, segundo ele, de romper a imagem do Sujeito. (TOURAINE, 1994, p. 177).

Portanto, segundo o ponto de vista acima, o centro da obra de Foucault está deslocado. Mas Touraine apresenta sua abordagem de Foucault dentro de um contexto amplo: a modernidade. Esta é a época em que nós vivemos, ela é interpretada como um grande conjunto de vários autores, que se caracterizam como críticos da sociedade moderna, principalmente no período após as duas guerras mundiais. A análise de um espectro tão grande deve estar atenta aos fenômenos da massificação e do consumo. Embora isso não seja enfatizado por Touraine, esses fenômenos estão relacionados diretamente aos desenvolvimentos tecnológicos alcançados nas últimas décadas. E tais fenômenos, considerados sociais, são os efeitos de uma junção, ainda mais remota, entre capitalismo e inovação. Para que essa junção seja bem sucedida é preciso que o desenvolvimento tecnológico se cumpra de forma eficaz. Tal eficácia tem ocorrido na época atual por meio da internet e da automação. Mas o direcionamento que Touraine assume é outro.

No amplo contexto que inclui Foucault, Touraine aborda outros autores como Horkheimer, Marcuse. Estes autores se apresentam como grandes fontes nutridoras de uma 
miríade de estudiosos posteriores, todos eles críticos do sujeito: "Intelectuais críticos, dede a Escola de Frankfurt, empenharam todas as suas forças na luta contra a ideia de Sujeito" (TOURAINE, 1994, p.181). Nessa amplitude, Touraine procura balizar com alguns pontos comuns dessas críticas, e concebe como comum às críticas certa superficialidade:

\begin{abstract}
A franqueza de quase todos os pensamentos da modernidade vem do fato de suporem a onipotência de um poder central, o do Estado ou o da classe dirigente, o que está próximo da representação, bem superficial, da história como conspiração. Ora, cada um pode constatar que as sociedades que acabam de ser chamadas democráticas tornam o poder central bem menos visível que outras, por vezes até invisível, que elas são tolerantes e até mesmo liberais. (TOURAINE, 1994, p. 174).
\end{abstract}

O autor considera que poder, sob a hegemonia do Estado, é superestimado. Há uma tolerância maior nas sociedades democráticas e um poder difuso: "por vezes até invisível". A respeito dessa invisibilidade é possível passar de uma crítica à modernidade, no âmbito acadêmico e teórico, para uma crítica baseada em fenômenos concretos e efetivos. Um exemplo desses fatos concretos está no livro de Cathy O’Neil (2016) sobre a tendenciosidade e o preconceito contido nos algoritmos, ao contrário da aura de neutralidade que se imagina que eles possuam. Dentro dessa compreensão, pode-se dizer que os algoritmos e os modos como eles carregam os preconceitos de quem os elabora, é um lado escuro da invisibilidade do poder, uma invisibilidade tão efetiva quanto perigosa.

Mas não é essa direção que Touraine está focando. Ele procura destacar as bases das críticas que foram surgindo ao longo do século XX. Essa perspectiva seria inadequada, porque presume a onipotência do Estado (ou da classe dirigente), mas para Touraine há sempre outra força em ação: o sujeito. Nessa seção a respeito de Foucault, Touraine afirma: "Não se pode falar de Sujeito a não ser lá onde intervém o poder, pois o apelo ao Sujeito é constitutivo do ator que se define contra a influência objetivante dos aparelhos." (TOURAINE, 1994, p.177).

Mas, no manancial teórico gerado pelas críticas ao sujeito, encontram-se alguns autores importantes que estavam atentos aos elementos mais implícitos nos grandes cenários de dominação. Uma atenção com tal refinamento inclui, dentro do processo que exerce a dominação, os próprios críticos do sujeito e da modernidade; entre esses autores importantes, Foucault. Touraine o distingue com as seguintes palavras:

Uma das forças do pensamento de Michel Foucault é que ele rejeita a ideia de uma repressão e de uma manipulação generalizadas, e mesmo de um poder central instalado como a aranha no meio de uma teia de funcionários e de agentes de propaganda. O movimento central do seu pensamento neste âmbito, o que lhe 
confere sua originalidade e explica sua influência, consiste em substituir a idéia de que o poder central não cessa de reforçar-se e de concentrar-se pela idéia inversa, a saber, que o próprio exercício do poder se confunde cada vez mais com as categorias da própria prática, de sorte que, na sociedade moderna liberal, o poder está em toda parte e em nenhuma parte, mas principalmente que a organização social, longe de ser regida pela racionalidade técnica, o é pelo exercício do poder. (TOURAINE, 1994, p. 174).

A referida "sociedade moderna liberal" é a sociedade democrática. É nessa sociedade que a discussão pode, preferencialmente, ser realizada. Nesse contexto específico, Touraine afirma que o "pensamento de Foucault" possui "originalidade" e "influência". Essas duas características permitem que ele analise o poder mesmo com os efeitos dessa mencionada invisibilidade. Evidentemente, não contra os efeitos da invisibilidade tecnológica e técnica como no caso dos algoritmos, pois essa inovação tecnológica não tinha ainda alcançado os seus efeitos de massa. Mas com Foucault podemos desvendar a invisibilidade, quando compreendemos a organização social como "regida" "pelo exercício do poder".

O caráter implícito repousa na dinâmica desse "exercício". Este é o resultado de uma análise não superficial. Por outro lado, dentro da superficialidade possível, existem apenas diversos aspectos difusos de que o "poder está em toda parte e em nenhuma parte". Sob essa perspectiva, a sociedade democrática está sob uma pressão muito mais complexa do que as sociedades não democráticas. Os seus problemas mais explícitos carregam consigo sempre a invisibilidade passível de ser desvendada e explorada. Mas essa invisibilidade existe também nos algoritmos, nos quais as dificuldades para desvendá-la são maiores.

Na passagem mais acima, Touraine afasta a possibilidade de que a "organização social" seja "regida pela racionalidade técnica". O seu livro foi publicado em 1992. Talvez nessa época o poder da racionalidade técnica no que diz respeito à relação entre humanos e softwares pudesse ser desprezado. Mas, na época atual com softwares preditivos com base em aprendizado (Machine learning) e assistentes de inteligência artificial, não podem mais ser desprezados. Em relação a isso, surge uma ameaça ainda não compreendida às democracias. Este artigo traz apenas uma sinalização a respeito.

Em 1994, Touraine afirmará que Foucault deixou de tratar sobre o sujeito em função de uma preocupação demasiada com o poder. É interessante que, mesmo assim, Touraine mantém uma espécie de vínculo com Foucault que se funda na originalidade deste e na resistência deste autor aos discursos hegemônicos em geral. Tais discursos seriam, sob o ponto de vista de Touraine, uma forma de silenciar o sujeito. O sujeito que serve como base ao ator nas lutas contra a opressão. Esse sujeito se destacaria por meio de uma autoelaboração 
e de uma auto-organização. Entretanto, um ponto importante separa ambos os autores: a subjetivação. Estabelecer essa diferença é importante, porque ela significa uma não adoção de caminho foucaultiano por parte de Touraine, principalmente nesses primeiros anos da década de 90. Podemos perceber uma separação nesta passagem:

\footnotetext{
Foucault tem razão de partir da objetivação que conduz às intervenções crescentes da sociedade sobre seus membros, mas esta objetivação, se ela é associada à individualização - tanto a do consumidor como a do "caso social" -, não produz subjetivação. Muito ao contrário, uma sociedade técnica e administrativa transforma o homem em objeto, o que expressa a palavra burocracia em seu sentido mais usual. (TOURAINE, 1994, p. 177).
}

É preciso ter em vista que a "racionalidade técnica" referida na citação anterior está ainda presente na "objetivação". Touraine discorda de Foucault quando este associa a individualização a uma objetivação e quando justapõe a objetivação como parte de um processo de subjetivação. Para Touraine, a subjetivação participa de um campo contrário: aquele da luta "contra a influência objetivante dos aparelhos" (citação supra, bem mais acima das anteriores). Para Foucault, a subjetivação visa a disciplina, a população e a governabilidade. Touraine, por seu lado, trata da individualização com a sua concepção de um "ator social", dentro do embate contra essa "influência objetivante dos aparelhos". Portanto, temos uma esperança na construção do sujeito, se as estruturas objetivantes forem combatidas. Touraine confirma essa discordância no livro Critica à modernidade: "O que importa para Foucault é demonstrar que o Sujeito foi criado pelo poder, isto é, pelo conjunto de mecanismos da microfísica do poder, portanto, pelos mecanismos objetivantes da normalização." (TOURAINE, 1994, p. 176). Essa sua posição ainda sofrerá uma modificação a partir do ano de 2000.

A reflexão propiciada por Touraine permite destacar dois elementos: a objetivação e a subjetivação. A objetivação consiste nos efeitos dos "mecanismos objetivantes da normalização" (TOURAINE, 1994, p.176). E a subjetivação é, nos dois autores, um campo aberto para a interpretação. À medida que a subjetivação vai sendo definida, outros temas podem ser. Nesse caso inclui-se a análise das formas de governo: democrático, autoritário etc. e, também, de vários fenômenos do mundo como as instituições da prisão, a repressão etc. Mas o importante é que essa relação entre subjetivação e objetivação permite assinalar diferenças a respeito do mundo concreto: 


\begin{abstract}
A situação na qual estas duas ordens, a da objetivação e a da subjetivação, se confundem é aquela em que o poder se identifica com a racionalização, como é o caso dos despotismos esclarecidos e, em nosso século, dos regimes comunistas, que são propriamente totalitários uma vez que eles instalam seu poder sobre sujeitosobjetos e cobrem com o nome de progresso os interesses particulares do PartidoEstado. A Análise de Foucault pode ser aceita como uma crítica dos regimes totalitários, mas ela não corresponde às situações nas quais o Estado e a sociedade civil estão separados e em que, sobretudo, a normalização em nome da razão não se confunde com o poder no que ele tem de repressivo. (TOURAINE, 1994, p. 177).
\end{abstract}

Para Touraine, em seus escritos nos anos 90, ainda é possível uma "normalização em nome da razão", porque, em "situações nas quais o Estado e sociedade estão separados", a "normalização em nome da razão não se confunde com o poder no que ele tem de repressivo". Esse tipo de normalização tem duas identificações possíveis na passagem acima: (a) uma identificação com a racionalização, mas com essa ressalva importante que estão de fora da análise os regimes totalitários; e (b) identificação que pode ser feita do sujeito, pois ele é a base do ator que se constrói através de uma ação contra os mecanismos objetivantes. Essa identificação (b) será explorada de forma diferente a partir de 2007.

Na sociedade democrática existem esses "mecanismos objetivantes", e na luta contra eles o sujeito se constrói. Resta explorar as diferenças entre "mecanismos objetivantes" e "a normalização em nome da razão”. Podemos afirmar que a reflexão de Touraine se aproxima e se afasta de Foucault. O afastamento é complexo. Essa complexidade pode ser caracterizada na compreensão original que Touraine possui dos movimentos sociais em 1992:

\footnotetext{
É a luta social que opõe o indivíduo-objeto ao indivíduo-sujeito, e somente o triunfo do poder, e esmagamento das lutas de contestação podem deixar o campo livre para uma representação do indivíduo como objeto, examinável e manipulável. Nem tudo é poder, e somente o poder absoluto, dessubjetivando o homem, chega a confundir racionalização e poder, suprimindo a capacidade e vontade de quase todos de agir como sujeitos. O que Foucault descreve mais demoradamente é o que eu chamo de antimovimentos sociais [movimentos de contracultura], enquanto ele não evoca, a não ser em passant, os movimentos sociais que introduzem a defesa do sujeito contra um poder que se apresenta como tecnocrático. (TOURAINE, 1994, p. 178)
}

Touraine não vai desenvolver muito aprofundadamente o caráter "técnico" que compõe a expressão "tecnocrático". Embora essa expressão possa ser compreendida como uma variação das tecnologias do poder sobre o corpo e da tecnologia da alma, utilizadas anteriormente por Foucault, ela também pode ser direcionada para uma invisibilidade mais difícil: a da tecnologia atual. Contudo, Touraine não faz essa incursão a respeito da tecnologia, pensando-a como uma ameaça à democracia. $\mathrm{O}$ seu foco é Foucault e a recusa de que a subjetivação seja a sujeição no embate das relações de poder. 
Mas ocorrem mudanças no pensamento do sociólogo francês a partir do século XXI. Muitos fatores contribuem para essa modificação, principalmente a sua posição de que o social e a sociedade estão em processo de decomposição. Surge a sua ideia de que o sujeito é a base de um ator não social, diferente daquela da década de 90, quando o sujeito ainda era considerado a base de um ator social. Essa mudança é expressa de um modo contundente como o "fim do social" (TOURAINE, 2009, p. 106-110). O que se modifica não é a concepção de sujeito, mas de ator. A concepção de sujeito permanece central: "O tema do sujeito e da democracia tornam-se inseparáveis quando a existência do sujeito é comandada pela sua dupla luta contra os aparelhos do poder comunitário e contra a lógica dos sistemas técnicos mercantilistas." (TOURAINE, 1996, p. 180).

A decomposição da sociedade e a afirmação do "fim do social" oferecem a Touraine a possibilidade de se aproximar mais estreitamente de Foucault. O resultado é uma certa tranquilidade em sua mudança de qualificação do ator: de social para não social. Munido dessa modificação, Touraine enfrenta o domínio do que ele denomina: discurso interpretativo dominante. Ele aborda esse tipo de discurso em seu livro de 2007 (ano da publicação em francês): Pensar outramente. Esse discurso é um "conjunto de princípios, de ideias, de lembranças, julgamentos, que não são determinados apenas por um entorno político nacional e internacional" (TOURAINE, 2009, p. 24). Esse discurso é difícil de distinção, pois "muitas vezes negamos a sua existência ao buscar no Estado e na economia internacional, as explicações diretas de nossas condutas" (TOURAINE, 2009, p. 25). Os "acontecimentos" e as "decisões por meio de representações" são parte de uma explicação, e "a explicação em Ciências Sociais consiste sempre em encontrar as correspondências entre as determinantes exteriores e o conjunto das demandas dos próprios atores" (TOURAINE, 2009, p. 25). Esses atores são aqueles que estão empenhados em desenvolver o sujeito e determinar a sua condição de indivíduo, mas os atores estão sob risco, porque o discurso interpretativo dominante os envolve:

É neste nível intermediário, aquele do discurso ideológico dominante, que se operam as escolhas intelectuais, que se forjam as condições de comunicação, as quais impõem regras, concedem um privilégio de escuta a alguns e não a outros, e às vezes chegam até mesmo a fazer considerar como natural e objetivo aquilo que não é senão o resultado de uma construção da realidade social repousando exclusivamente sobre ela mesma e sobre a importância de seu papel. Este discurso ideológico é igualmente afastado do poder do Estado, que pode ser a autoridade da ciência ou a influência dos intelectuais criativos. Podemos chamar de discurso interpretativo dominante este conjunto de representações que constitui uma 
mediação, mas sobretudo a construção de uma imagem da vida social e da experiência individual. (TOURAINE, 2009, p. 25).

Uma das consequências do discurso interpretativo dominante é que ele "levanta barreiras que não tem qualquer existência oficial, mas difíceis de serem superadas; ele restringe o conhecimento dos fatos ao lhes dar uma interpretação a priori” (TOURAINE, 2009, p. 27). Essas consequências se manifestam quando o discurso interpretativo dominante com confrontado com o tema do ator. Touraine vai contrapor sempre a ação do discurso interpretativo dominante ao ator, pois segundo ele, na ótica desse discurso dominante, há um objetivo: alcançar um "mundo sem atores":

[...] o discurso interpretativo dominante tem construído um mundo sem atores, dominado por lógicas implacáveis que se infiltram por toda parte, em todas as categorias do conhecimento e da organização social. Ele não é uma da história social em seu conjunto, nem mesmo das relações sociais; ele não é absolutamente a análise de uma consciência de classe ou de uma consciência política; é uma visão puramente crítica da vida social dominada por um poder absoluto. (TOURAINE, 2009, p. 28).

O discurso interpretativo dominante não é o mesmo que um discurso oficial e, o seu efeito sobre os atores mais extenso do que aquele efeito causado pelo discurso oficial. Mesmo na época em que Touraine não considerava a sociedade como se decompondo, e o ator era social, o discurso interpretativo dominante é dirigido contra o ator. Touraine usa palavras fortes a respeito, note-se que ele menciona o ator "social" e não o ator "não social":

O discurso interpretativo dominante não é, pois, um conjunto de ideias vagamente associadas umas às outras; ele é a construção de uma arma voltada contra a definição do ator social como alguém capaz de afirmar-se por si mesmo, e de defender seus direitos enquanto finalidade principal de sua própria ação. (TOURAINE, 2009, p. 47).

A diferença entre ator social e ator não social cria um espaço em relação ao qual o discurso interpretativo dominante perde por alguns momentos o seu foco. $\mathrm{O}$ discurso interpretativo dominante é muito eficaz na sociedade, mas quando a sociedade está se decompondo e existe um "fim do social", esse tipo de discurso simplesmente procura visar o ator. Mas a sua eficácia contra esse ator não social e "o pior inimigo de todos os sistemas de poder" (TOURAINE, 2009, p. 47) é menor, pois falta a dimensão "social”. O que falta, também, nesse quadro geral é a relação entre o "fim do social" e as novas tecnologias de software do século XXI. Essas tecnologias decidem investimentos e contratação de 
empregados por meio de modelos a partir de banco de dados pessoais. Mas os critérios da execução desses modelos, critérios que podem conter preconceitos, não são visíveis.

Mas Touraine é muito lúcido ao afirmar que o centro da crise atual são as representações que temos da sociedade industrial:

\begin{abstract}
O que está em crise, e provavelmente em declínio, é a representação da sociedade estruturada por relações de classes, formada no coração da sociedade industrial; e isso porque esta visão corresponde sempre mais às sociedades pós-industriais em que vivemos. O DID [discurso interpretativo dominante], pois, está sempre mais direcionado para o Estado e para o seu controle da sociedade, chegando inclusive a negar a existência dos atores e dos movimentos sociais. É soma destes dois desvios que melhor explica o fato desta visão de sociedade se manter, e inclusive, divulgar sua dificuldade de perceber e de compreender as novas realidades. (TOURAINE, 2009, p.51).
\end{abstract}

Entre essas novas realidades está a interface ou embate com os atores "não sociais". As novas realidades são novos fenômenos que mostram a decomposição da sociedade: a "sociedade como combinação de formas de inteiração, de sistemas de decisão, de agentes de aculturação e de repressão, em toda a parte, está se decompondo.” (TOURAINE, 2009, p. 106). Na democracia, a decomposição está presente, quando o autor contrapõe possíveis "dirigentes selvagens" aos dirigentes que seriam os democráticos, "[...] vemos criar-se um mundo completamente desorientado antes de um mundo vítima da barbárie de dirigentes selvagens" (TOURAINE, 2009, p.107).

A caracterização do mundo atual como um "mundo desorientado", no qual a sociedade está "se decompondo", abre a possibilidade para se apresentar uma alternativa. Essa alternativa seria o "mundo do sujeito". Um mundo que dependeria da luta e da construção do sujeito. Há, portanto, a união de dois fenômenos: do fenômeno da decomposição da sociedade e do fenômeno de um mundo do sujeito. Essa união se mostra profícua e é apresentada na seguinte passagem:

Para além da ruptura e do enfraquecimento das instituições, eu particularmente vi no "fim do social" um confronto face a face entre o mundo "objetivo", o do mercado, das tecnologias e também da guerra, e o mundo do sujeito, justamente por ele estar diretamente engajado na sociedade presente, enquanto que, nas sociedades de um passado recente, ele escondia-se por detrás das imagens do cidadão, do trabalhador. Todavia, estou ciente de que este discurso repousa sobre uma confiança na ação libertadora do sujeito e dos movimentos sociais, confiança que acredito justificada e mesmo necessária, mas que não deve fazer esquecer a face sombria de morte que recebe este movimento do "fim do social". O que esta noção introduz, de fato, é a decomposição interna das condições de formação dos atores. O que é bem diferente dos fenômenos de dominação, de colonização ou de destruição que conhecemos tão continuamente durante o período clássico do modelo europeu, ele mesmo voltado 
acima de tudo para a conquista do mundo exterior. Nós passamos dos problemas que poderíamos definir de dominação e de exploração para novos problemas que certamente devem ser definidos em termos de decomposição e de dessocialização, por um lado, mas também de construção mais direta do sujeito por ele mesmo, por outro lado. (TOURAINE, 2009, p.108-109).

É importante destacar esta expressão: mundo "objetivo" (Touraine coloca entre aspas) como o mundo do mercado e, principalmente, das "tecnologias". Nós retomaremos essa expressão na segunda parte deste artigo. Touraine é otimista, pois para ele onde há opressão, também há possibilidade de emergir o sujeito. Assim, a "ação libertadora do sujeito" deve se confrontar com duas oposições: com o discurso interpretativo dominante e a imersão na tecnologia. E este confronto é mais possível e mais explícito nas democracias.

O cenário da política, em um regime democrático, possui um discurso interpretativo dominante. Este discurso, que procura silenciar e destruir o sujeito, é uma "arma contra o sujeito" (citação supra). Há uma falta de foco desse discurso, quando o autor não vai falar mais de um "ator social". O ônus dessa falta de foco recai sobre o próprio discurso interpretativo dominante. Finalmente, Touraine assumirá o termo "ator não social" como uma forma de resistência ao mundo "objetivo" do mercado e das "tecnologias". Esse ator não social possui o potencial de uma "ação libertadora". Mas a crise da democracia pode estar localizada justamente nesse hiato entre a sociedade e o ator não social, entre a tecnologia e as ações desse ator não social. E a discussão dessas possibilidades, no mundo democrático e “objetivo", tomado pelas “tecnologias”, será feita na próxima seção.

\section{O ATOR "NÃO SOCIAL" E A TECNOLOGIA}

Em Pensar outramente, Touraine anuncia uma mudança na sua concepção de ator. E um dos eixos que serve para explicar essa mudança foi Foucault. No seu livro anterior de 1992 (editado em português em 1994: Crítica à modernidade), Touraine tinha uma posição diferente sobre Foucault, pois ele compreendia que Foucault "permaneceu constantemente ligado a uma visão puramente crítica, à denúncia do Sujeito como um efeito do poder, mas a sua obra não lhe pertence completamente e ela é muito rica para ser doutrinária" (TOURAINE, 1994, p.178). Em 2007, ano da edição do original em francês de Pensar outramente, Touraine se inspira nas publicações dos últimos cursos de Foucault. E encontra nelas os subsídios para combater o que ele denominou de "discurso interpretativo dominante". 
Com esta mudança, o Foucault de Hermenêutica do sujeito é visto como um "barqueiro" que metaforicamente auxilia numa travessia:

\begin{abstract}
Michel Foucault nada mais é do que grande barqueiro. Este partindo de sua oposição a Sartre, e atravessando os maiores temas do discurso interpretativo dominante, alcança a ideia de sujeito e de subjetivação que nos libertam do sufoco imposto pela noção de uma sociedade sem atores, sem reflexão e sem consciência. É por isso que fiz aqui uma peregrinação ou um desvio para o Foucault dos últimos anos antes de expor mais diretamente minha reflexão, que cruza uma etapa da sua e que se sente confortada e até mesmo legitimada por seu esforço inovador. (TOURAINE, 2009, p. 101).
\end{abstract}

Para Touraine (2009, p. 87), Sartre foi um dos "melhores autores" que difundiram o discurso interpretativo dominante. Por isso aquele começa a citação acima opondo Foucault a Sartre. Nesse contexto, ele continua afirmando a sua própria reflexão como "confortada e até mesmo legitimada" a partir do caminho apresentado por Foucault em seus últimos cursos. Este último liberta a reflexão do "sufoco imposto pela noção de uma sociedade sem atores, sem reflexão e sem consciência". Tal libertação se reveste da nova forma assumida pelo ator como não social. E, nessa libertação expõe a dependência que o discurso interpretativo dominante possui em relação ao social (na forma de Estado, de sociedade, e de atores sociais). $\mathrm{Na}$ época atual, a situação de crise de um regime democrático pode ser explicada justamente pela ausência de um ator social. Há ausência de alvo que esvazia o discurso interpretativo dominante e, isto é uma parte importante de uma democracia em crise.

Foucault o auxilia a fazer a travessia que vai do "social" para o "fim do social". Pois Foucault revira do "avesso" o bloqueio instalado pelo discurso interpretativo dominante (TOURAINE, 2009, p. 99). Segundo Touraine, o motivo pelo qual Foucault revira do avesso o discurso dominante é uma reação à incompreensão de sua obra. Na interpretação de Touraine, essa incompreensão possibilitava um uso das ideias de poder e de dominação para fins de ocupação do espaço de discussão aberto e disponível nas democracias. Essa ocupação tinha como efeito o silenciamento do sujeito e desarme intelectual dos atores. Finalmente, para convergir a interpretação sobre Foucault com a ideia de sujeito, Touraine apontará as "reflexões de si sobre si":

[...] é exatamente porque Foucault ocupou um lugar preponderante dentro da corrente dominante que se faz necessário mostrar que ele igualmente foi um de seus principais críticos. Bem antes deste período de sua vida, que começou com suas interrogações sobre seu vasto projeto de uma história da sexualidade, introduzida pelo livro La volonte de savoir [...], numerosas vezes ele manifestou sua irritação diante daqueles que lhe faziam dizer que o saber é o poder, ideia que ele rechaçava 
totalmente, já que ela tornava incompreensível grande parte de sua própria obra. Desde aquele momento, ele insiste em esclarecer que o objetivo central de sua vida foi "sempre a verdade, dizer a verdade, Wahr sagen, aquilo que diz a verdade". Mas, imediatamente acrescenta: "E a relação entre dizer verdade forma-se de reflexões, reflexões de si sobre si”. (TOURAINE, 2009, p. 99).

Agora o contexto teórico de Touraine fica alterado, a compreensão do ator enquanto “não social” será utilizada nos livros posteriores. Assim, três anos após o livro Pensar outramente, Touraine escreve e publica Après La crise (2010 em francês, publicado em português em 2011). Nessa obra a crise financeira de 2008-2009 tem um destaque: ela assinalou a separação entre economia e sociedade. Nessa separação, os atores sociais não conseguiram esboçar uma reação à altura dos acontecimentos: inúmeros trabalhadores foram demitidos e se tornaram desempregados, fora propriamente de uma sociedade de consumo. Eles eram atores sociais quando empregados, passaram a ser não mais atores sociais e, em alguns casos, nem mesmo atores. A reação só pode vir de um âmbito: o âmbito não social, baseado em valores morais e culturais. Essa ração foi conduzida por atores não sociais.

$\mathrm{Na}$ nova obra Touraine relembra que a sua concepção de atores sociais os vinculava às suas funções sociais e, com a decomposição da sociedade, esses atores perdem a sua força de reação. Por outro lado, a direção para a qual se movem estes atores não sociais é outra:

\footnotetext{
[...] do lado dos atores nos concentrávamos em sua função social. Ora, exatamente hoje, os atores não são mais analisáveis deste ponto de vista. Pode-se mesmo afirmar que esta redefinição dos atores, não mais como atores sociais, mas atores morais e pessoais, é comandada por uma situação tornada ela mesma não social e que engaja os indivíduos, os grupos e as instituições enquanto defensores (ou, ao contrário, adversários) de determinadas fontes de legitimidade. Quando a separação entre sistema atores torna-se total, os atores não podem mais ser definidos como atores sociais, já que sua legitimidade vem de uma instância acima. Ela provém daquilo que carrega consigo o sujeito, isto é, os direitos. (TOURAINE, 2011, p. 122).
}

Essa nova direção assinala as características "morais e pessoais" dos atores, e elas transparecem em suas exigências reivindicatórias. Ele afirma que "o mais importante destes direitos é aquele de ser ator, o que Hannah Arendt expôs com a maior força definindo os seres humanos por seu "direito de ter direitos"” (TOURAINE, 2011, p. 122). Por meio dessas características, percebe-se a evolução do conceito de ator em Touraine, o que mantém a concordância com o seu principal tema: o sujeito. Este está vinculado diretamente à democracia, como por exemplo, já no seu livro de 1994: Qu'est-ce que la democratie? Ele afirmava: 
[...] a democracia é o regime que reconhece os indivíduos e as coletividades como sujeitos, isto é, os protege e encoraja em sua vontade de "viver sua vida" e dar unidade e sentido à sua experiência vivida. Nesse caso, o que limita o poder não é somente um conjunto de procedimentos, mas a sua vontade positiva de aumentar a liberdade de cada um. A democracia é a subordinação da organização social, e, particular, do poder político, a um objetivo que não é social, mas moral: a libertação de cada um. (TOURAINE, 1996, p. 254).

O foco nesta época é, também, a moral: "A democracia é a subordinação" de todo um conjunto que inclui "organização social" e "poder político" perante a "moral”. Assim, o que difere no seu trabalho mais recente, é a consideração de que a sociedade se decompõe e de que o ator não possui mais uma função social, mas um papel moral: "Esta separação entre o sujeito e o sistema, isto é, em uma palavra, o desaparecimento do ator social, desde o Século das Luzes foi acompanhada por apelos aos sujeitos que hoje não se dirigem mais a um sujeito social, mas a um sujeito pessoal, moral." (TOURAINE, 2011, p. 186-187, grifos do autor).

Mas, no século XXI, é preciso assinalar que o sujeito, base do ator não social, está cercado por dispositivos tecnológicos que possuem uma invisibilidade de instruções internas (algorítmicas), na maior parte das vezes, indevassáveis. Isso afeta todas as comunicações, seja entre atores ainda sociais ou não sociais. As demandas dos atores são encaminhadas de uma forma diferente do que ocorria nas sociedades industriais. Essas demandas podem ser identificadas, e os atores podem ter os seus dados armazenados e mais tarde classificados e utilizados em uma possível manipulação. Essa manipulação é matemática, pois remete diretamente ao funcionamento dos algoritmos e depende apenas das formulações do programador, ou o que é ainda mais inescrutável, da formulação modeladora de um software de aprendizado de máquina (Machine learning). Em ambos os casos, há uma perigosa ameaça à democracia, mas ela é silenciosa e revestida por um enganoso manto de neutralidade tecnológica.

Entretanto, Touraine não se deixa atentar para esse tipo de ameaça. Em seu próprio caminho ele pergunta como a liberdade se efetiva na luta dos atores morais não sociais. Lutas essas que devem ser diferentes das lutas anteriores pela modificação das relações de produção:

O objetivo destas observações é aquele de insistir sobre o fato de que na situação pós-social não é mais na vida "social" ou econômica que se travam os combates pela liberdade. A eliminação de uma forma de dominação não liberta aqueles que eram dominados; ela abre o caminho para uma nova forma, menos brutal, mas talvez mais estreita, de "vigilância", no sentido dado a este termo por Michel Foucault. Falar de 
libertação pelo trabalho, ou ainda por uma revolução que transforma as relações sociais de produção, tem cada vez menos sentido; na verdade, estas "grandes narrativas", na expressão de Jean-François Lyotard, realmente já não contam mais com tantos defensores. (TOURAINE, 2011, p. 138).

Na passagem acima, Touraine deixa entrever uma possibilidade que ele não explora, mas que tem relação direta com o uso da tecnologia na nossa época atual. Trata-se do seu breve comentário a respeito de que a vigilância pode ser "mais estreita". Esse contexto de vigilância digital está presente nas democracias existentes e é um dos elementos para um possível direcionamento ou manipulação da ação desses atuais atores não sociais. Diante dessa possibilidade, dois procedimentos de poder genéricos podem ser realizados sobre os atores não sociais: a coleta de dados e o direcionamento do foco e da ação dos atores. Evidentemente, esses dois procedimentos são genéricos e constituem uma ameaça potencial no desenvolvimento do sujeito em atores não sociais. Vamos ilustrar esses dois procedimentos abaixo.

Em relação à coleta de dados, hoje em dia, esta é um procedimento comum para fins de publicidade e venda na internet. Mas, para um aprofundamento, podemos utilizar a contextualização de Andy Müller-Maguhn, em livro que é um diálogo com J. Assange e outros. O livro questiona a liberdade e internet. Em um trecho, Müller-Maguhn fala sobre como exercer a vigilância a partir da captura e do armazenamento de dados. A sua declaração foi publicada em 2012, um ano seguinte ao livro Após a crise, de Touraine. Não há porque pressupor uma ligação entre ambos, a não ser uma ligação sobre o sujeito ser livre, se comunicar livremente e se organizar para reivindicações enquanto um ator não social. Se o sujeito, base do ator não social, não pode ser livre e com sua privacidade respeitada, então há aqui, certamente, uma ameaça à democracia. As palavras de Müller-Maghun são as seguintes:

[...] nos dias de hoje, é considerado muito eficiente dizer: "Vamos pegar tudo e esmiuçar depois". Então eles de fato têm um armazenamento de longo prazo, e a melhor maneira de descrever essas duas eras da indústria de vigilância, é em termos da abordagem "tática" e da abordagem "estratégica". Uma abordagem tática seria algo como: "Nesse exato momento, nessa reunião, precisamos grampear esse lugar, precisamos plantar alguém com um microfone ou deixar sistema de vigilância GSM [Global System for Mobile Communications] de prontidão em um carro para interceptar imediatamente o que as pessoas dizem sem precisar envolver a operadora da rede, sem precisar obter um mandato de busca ou algo parecido, sem necessidade de nenhum procedimento legal.... É só fazer”. Já a abordagem estratégica significa fazer por defaut - simplesmente gravar tudo e esmiuçar depois, por meio de sistemas analíticos. (ASSANGE et al., 2013, p. 57). 
Essa passagem mostra o uso de desenvolvimentos tecnológicos disponíveis no ano de 2012. É razoável supor que esses desenvolvimentos foram aperfeiçoados. Basicamente o processo é de captura em massa de informações (formação de um Big Data) e, depois, uma "mineração" para proceder a uma análise por um software que identifica padrões e faz previsões (Machine learning). Esses desenvolvimentos tecnológicos não são fícção, são realidades existentes na época atual e fazem parte do mundo “objetivo", conforme a expressão utilizada por Touraine, mencionada na primeira seção. Não reconhecer a existências e ação desses softwares significa se embrenhar cada vez mais na invisibilidade de uma forma de controle e poder.

Além dessa captura de informações para uma possível análise posterior, no mundo “objetivo" das tecnologias, há igualmente a possibilidade de manipulação das opiniões, por exemplo, nas redes sociais. Essa manipulação sem dúvida tem uma faceta técnica, o que contribui para sua "invisibilidade". Um é o uso nas redes sociais de "robôs sociais". Esses softwares avivam polêmicas entre os usuários de uma rede para conduzir as opiniões para uma determinada direção. Eles são algoritmos que aparecem como perfis de usuários e chegam a fazer duas postagens por segundo, e podem atuar em mais de uma rede social ao mesmo tempo. Exemplos concretos dessa manipulação foram pesquisados na política brasileira. Esses exemplos podem ser vistos na publicação do DPPA da Fundação Getúlio Vargas (RUEDIGER, 2018). Pode-se acrescentar, também, o escândalo em 2018 do uso de dados de milhões de usuários do Facebook por uma empresa de Machine Learning, a Cambridge Analytica (BBC, 2018).

Por meio desses dois procedimentos genéricos: a coleta de dados (Big Data) e manipulação a partir de padrões iniciais (Machine Learning), que mundo "objetivo" das tecnologias apresenta mais desafios ao sujeito de Touraine do que se poderia suspeitar. $\mathrm{O}$ desvelamento de seus aspectos e as formas de enfrentamento são ações possíveis de ocorrer em democracias, ao contrário de regimes totalitários. E a complexidade da tarefa envolvida permite a desconfiança que essa mesma tarefa não seja suficiente para o sujeito. A esperança, por assim dizer, a respeito da contribuição de Touraine, é que ele inclui esses novos desafios, sem nomeá-los sob o signo de "novos enfretamentos”. As suas palavras são:

Os novos atores não são mais sociais e devem identificar-se com a defesa daqueles direitos de alcance universal. A dificuldade de precisar a extensão do grupo dos atores será compensada pelo caráter radical dos novos enfrentamentos. Os novos atores devem, portanto, guiar-se por uma consciência muito forte de seus direitos e daquilo que os ameaça. (TOURAINE, 2011, p. 131). 
Os novos atores podem se guiar por uma "consciência muito forte dos seus direitos", mas talvez não possam dimensionar exatamente o que seja "aquilo que os ameaça", se formos fazer uma consideração dessa ameaça em termos tecnológicos. Isso significa que nas democracias, que são ambientes abertos, os atores podem ter, mesmo assim, muitas dificuldades para compreender e lidar com os desenvolvimentos tecnológicos que entretecem uma rede de invisibilidade, enganosamente recoberta pela pretensa neutralidade da técnica dos algoritmos.

O contexto como um todo se torna ainda mais complicado para uma liberdade e uma tomada de decisão autônoma. Quando Touraine assinala a vinculação entre "a criação técnica e científica" com o sujeito, o seu objetivo é tratar sobre o que seria essencial em uma "política do sujeito". As palavras são as seguintes:

\begin{abstract}
É por isso que a criação técnica e científica de métodos e de produtos novos deve estar no coração de uma política do sujeito. No instante em que a globalização dos mercados aparece para muitos como o princípio mesmo da economia, faz-se necessário lembrar que a inovação aportou à economia mais recursos do que a acumulação de capital. E longe de reduzir os Estados Unidos a um mero lugar de um neoliberalismo sem atores, é necessário lembrar que este país também é, de longe, o maior inventor e maior criador de métodos e de produtos. Inúmeras críticas foram endereçadas à nação schumpeteriana de ser empreendedora, mas ela tem o mérito de conferir um lugar central à invenção e à criação na análise econômica. (TOURAINE, 2011, p. 88-89).
\end{abstract}

Percebe-se que há aqui um problema importante: existe uma imprevisibilidade fundamental na ação do ator, pois ele pode estar simplesmente criando novos "métodos e produtos" para a coleta de dados e manipulação. Se esse ator é o mesmo que o ator "não social" de Touraine que reage contra "os mecanismos objetivantes" (1994, p.176) é algo que ainda está pendente. A invenção de "métodos e produtos" está propiciando também um aumento na possibilidade de vigilância e/ou controle, por um lado, e a possibilidade de manipulação das pessoas, por outro. Esses dois lados conformam a ameaça ou, no mínimo, uma parte da explicação da crise da democracia. Isso se deve por causa do ataque à privacidade (pela coleta de dados) e pela perda de autonomia (manipulação potencial ou efetiva). A "criação técnica e científica de métodos e de produtos" e o sujeito (enquanto ator não social) se unem no que denomina de "fim do social" ou decomposição da sociedade. Se a democracia depende fundamentalmente do sujeito e depende de que o sujeito possa se mostrar como um ator não social (de transformação ou de libertação), então este embate com a 
tecnologia disponível está se tornando cada vez mais urgente. Pois é possível que a coleta e a manipulação se constituam efetivamente uma barreira e uma ameaça à existência do sujeito. É como se os desenvolvimentos tecnológicos da sociedade pós-industrial atravessassem o âmago da democracia, prevendo e inviabilizando sem alarde toda ação possível do ator não social.

\section{CONSIDERAÇÕES FINAIS}

Este artigo procurou mostrar quais são as ameaças ao sujeito nos espaços democráticos. Para uma definição de sujeito, adotamos a posição de Touraine de que sujeito é a base da construção dos atores, sejam eles "sociais" (fase inicial de Touraine), sejam eles "não sociais" (fase mais recente de Touraine). Na primeira parte mostramos as características do discurso interpretativo dominante. Essas características são: esse discurso não se confunde com o discurso oficial, ele destaca "a onipotência de um poder central, o do Estado ou da classe dirigente"; há uma invisibilidade do poder nas democracias - ao longo do texto nós estendemos essa invisibilidade aos desenvolvimentos tecnológicos; e, por fim, o discurso interpretativo dominante procura silenciar o sujeito, constituindo-se em uma "arma" contra ele. Para reverter o caráter implícito do poder e enfrentar o discurso interpretativo dominante, Touraine encontra alguns sinais em Foucault. Este último mostrou que o exercício do poder era mais importante do que a substancialidade do poder. Depois de colocar os principais pontos, essa primeira parte termina mencionando a nova fase de Touraine. Esta se caracteriza pela afirmação do "fim do social". Permanece aqui, no entanto, ainda não aprofundado o tema da tecnologia e sua ação sobre o sujeito.

A segunda parte trata do mundo "objetivo" das tecnologias e o hiato entre sociedade e o ator não social. Para realizar essa análise, mais uma vez é utilizado o fio condutor da posição de Touraine frente a Foucault. A publicação dos últimos cursos de Foucault reconforta e legitima a passagem da reflexão de Touraine do social para o "fim do social". Ele encaminha essa separação a uma valorização das características morais e culturais dos atores não sociais. Neste ponto retorna o tema da invisibilidade do poder, esse retorno a coloca para além do discurso interpretativo dominante. A invisibilidade é situada nos desenvolvimentos dos dispositivos tecnológicos em procedimentos genéricos que podemos chamar de coleta de dados (Big Data) e de manipulação a partir de padrões (Machine Learning). A invisibilidade da tecnologia se constitui uma ameaça aos atores dentro dos campos abertos das democracias. 
Diante do quadro formado pelas duas partes antes referidas, podemos afirmar que a resposta para a pergunta principal - quais são as ameaças ao sujeito no espaço disponível da democracia? - é de que essas ameaças advêm não somente do âmbito do discurso (que assume a forma do discurso interpretativo dominante, não oficial, mas intelectual), mas advêm dos recursos tecnológicos atuais, como a coleta de dados, a análise preditiva e possível manipulação por meio de "robôs sociais". Com esta resposta contribuímos para uma ampliação da reflexão de Touraine para integrar mais o mundo objetivo das tecnologias.

\section{REFERÊNCIAS}

ASSANGE, J. et al. Cypherpunks: liberdade e o futuro da internet. Tradução Cristina Yamagami. São Paulo: Boitempo, 2013.

BBC. Facebook - Cambridge Analytica data scandal. Disponível em: <http: //www.bbc.com/news/topics/c81zyn08881t/facebook-cambridge-analytica-data-scandal>. Acesso em: 23 abr. 2018.

O'NEIL, Cathy. Weapons of math destruction: how big data increases inequality and threatens democracy. New York: Crown, 2016.

RUEDIGER, M. A. (Coord.) Robôs, redes sociais e a política no Brasil: estudo sobre interferências ilegítimas no debate público na web, riscos à democracia e processo eleitoral de 2018. Rio de Janeiro: FGV, DAPP. 2017. Disponível em: <http://dapp.fgv.br/robos-redessociais-e-politica-estudo-da-fgvdapp-aponta-interferencias-ilegitimas-no-debate-publico-naweb/> Acesso em: 30 mar.2018.

TOURAINE, Alain. Crítica da modernidade. Tradução Elia Ferreira Edel. Petrópolis, RJ: Vozes, 1994.

TOURAINE, Alain. O que é democracia? Tradução Guilherme João de Freitas Teixeira. Petrópolis, RJ: Vozes: 1996.

TOURAINE, Alain. Um novo paradigma: para compreender o mundo hoje. Tradução de Gentil Avelino Titton. Petrópolis, RJ: Vozes, 2006.

TOURAINE, Alain. Pensar outramente: o discurso interpretativo dominante. Tradução de Francisco Morás. Petrópolis, RJ: Vozes, 2009.

TOURAINE, Alain. Após a crise: a decomposição da vida social e o surgimento de atores não sociais. Tradução de Francisco Morás. Petrópolis, RJ: Vozes, 2011. 